\title{
Prognostic value of performance status in metastatic renal cell carcinoma patients receiving tyrosine kinase inhibitors: a systematic review and meta-analysis
}

\author{
Yawei $\mathrm{Xu}^{1+}$, Yuanyuan Zhang ${ }^{2+}$, Xianhao Wang ${ }^{1}$, Jiaqi Kang ${ }^{1}$ and Xiaoqiang Liu ${ }^{1 *}$ (D)
}

\begin{abstract}
Background: The association between performance status (PS) and the prognosis of metastatic renal cell carcinoma (mRCC) patients receiving tyrosine kinase inhibitors (TKIs) remains controversial. The aim of this study is to evaluate the prognostic value of PS in MRCC patients treated with TKIs.

Methods: Electronic databases were searched to identify the studies that had assessed the association between pretreatment PS and prognosis in mRCC patients receiving TKIs. Hazard ratios (HRs) and 95\% confidence interval (CI) for overall survival (OS) and progression-free survival (PFS) from eligible studies were used to calculate combined HRs. The heterogeneity across the included studies was assessed by Cochrane's $Q$ test and $P$ statistic. The Begg's funnel plot and Egger's linear regression teats were used to evaluate the potential publication bias. The meta-analysis was performed with RevMan 5.3 and Stata SE12.0 according to the PRISMA guidelines.
\end{abstract}

Results: A total of 6780 patients from 19 studies were included in this meta-analysis. The results showed that a poor PS was an effective prognostic factor of both OS (pooled HR: 2.08, 95\% Cl: 1.78-2.45) and PFS (pooled HR: $1.51,95 \%$ Cl: 1.20-1.91). Subgroup analysis revealed that poor PS significantly associated with poor OS and PFS in studies using Karnofsky PS scale (OS, pooled HR: 2.20, 95\% Cl: 1.65-2.94; PFS, pooled HR: 1.74, 95\% Cl: 1.19-2.56), conducted in Asia (OS, pooled HR: 2.25, 95\% Cl: 1.71-2.95; PFS, pooled HR: 1.73, 95\% Cl: 1.14-2.64) and NewcastleOttawa Scale score of 8 (OS, pooled HR: 2.61, 95\% Cl: 1.92-3.55; PFS, pooled HR: 2.43, 95\% Cl: 1.36-4.33).

Conclusions: This study suggests that a poor PS is significantly associated with poor prognosis in mRCC patients receiving TKIs.

Keywords: Metastatic renal cell carcinoma, Performance status, Prognosis, Mete-analysis

\section{Background}

Renal cell carcinoma (RCC) is the most common cancer of kidney in adults [1]. Nearly half of RCC patients eventually progress to metastatic RCC (mRCC), and the 5-year survival rate of these patients is poor [2, 3]. The molecular mechanisms of the pathogenesis have been widely investigated and has promoted the development of targeted agents in the past few decades [4]. Tyrosine kinase

\footnotetext{
* Correspondence: 13132133180m@gmail.com

†Yawei Xu and Yuanyuan Zhang contributed equally to this work

${ }^{1}$ Department of Urology, Tianjin Medical University General Hospital, 154

Anshan Road, Heping District, Tianjin 300052, China

Full list of author information is available at the end of the article
}

inhibitors (TKIs), which target the vascular endothelial growth factor pathway, have been approved for the first-line or later line of treatment for mRCC [5-7]. The TKIs, such as sorafenib, sunitinib, axitinib and pazopanib, have been consistently demonstrated in clinical trials to prolong both overall survival (OS) and progression-free survival (PFS) in patients with mRCC [6-8]. However, these targeted agents have provoked marked changes in the management of RCC, and new predictive and prognosis clinical markers are required.

Many previous studies have demonstrated that the prognosis of mRCC patients treated with TKIs varies greatly after treatment $[7,9]$, so it is important to assess which

(c) The Author(s). 2019 Open Access This article is distributed under the terms of the Creative Commons Attribution 4.0 International License (http://creativecommons.org/licenses/by/4.0/), which permits unrestricted use, distribution, and 
patients may benefit from TKIs before treatment. Performance status (PS) is used to quantify quickly the general well-being of people with illness and their ability to perform activities of daily living [10]. It is usually a proxy measure estimated by clinician and influences the decision to apply treatment regiments [11-13]. PS has been identified as an independent prognostic factor in several cancers, such as bladder cancer [12], lung cancer [11] and liver cancer [13]. Previous reports have shown that a poor PS predicts poor survival of patients with metastatic RCC [14-16]. However, the prognostic value of PS in patients with mRCC treated with TKIs is controversial. Bamias et al. found that PS was an independent prognostic factor (HR: 3.04, 95\% CI: 1.466.33, $p=0.003$ ) for mRCC patients receiving TKIs [17], and several other studies have drawn similar conclusions [1820]. But there were also studies have shown no significant relationship between PS and prognosis [21-26], such as a retrospective study of 257 patients by Hwang et al. (HR: 1.71, 95\% CI: 0.74-3.95, $p=0.21$ ) [26].

Furthermore, the association between PS and survival outcomes in patients with $\mathrm{mRCC}$ receiving TKIs has not been previously reviewed. Therefore, we conducted a systematic review and meta-analysis to evaluate the prognostic value of pretreatment PS in mRCC patients receiving TKIs.

\section{Methods}

\section{Systematic search strategy}

We conducted a systematic search of electronic databases, including PubMed, Embase, Web of Science and the Cochrane Library (updated 1 May 2018), to identify all relevant studies. The studies were searched using the terms "renal cell carcinoma or kidney cancer" AND "performance status or PS" AND "prognosis, survival or outcomes". The language of publication was limited to English. In cases of multiple reports from the same series, we used the most recent one. And we also searched the lists of eligible articles. Two investigators independently completed all the work the search strategy, filtered the titles and abstracts of all articles according to the following eligibility criteria.

\section{Eligibility criteria}

The eligibility criteria of studies included in this meta-analysis were listed as: (1) retrospective studies focused on the value of PS in predicting prognosis in patients with mRCC; (2) patients who received TKIs therapy mRCC; (3) hazard ratios (HRs) and 95\% confidence intervals (CIs) for overall survival (OS) or progression-free survival (PFS) should be reported in the articles or have enough information to calculate them; (4) pretreatment PS measured before administering TKIs.

\section{Data extraction}

The data was extracted by two investigators and the other two were responsible for checking. All authors have discussed the disagreements until a consensus was reached. A standardized form was created and used to extract available data from all eligible publications including the first author's name, publication year, region, study period, the number of patients, duration of follow-up, age, gender (male/female), tumor histology, type of PS, HRs, 95\% CIs and its $P$ value. If multiple HRs were presented in the original articles, we extracted the estimates from the largest adjusted model to reduce the risk of possible unmeasured confusion.

\section{Quality assessment}

Two investigators independently assessed the quality of all included studies. The Newcastle-Ottawa Scale (NOS) system was designed to evaluated the quality of non-randomized studies in meta-analysis [27]. It assessed study quality by 3 classifications including selection, comparability and outcome with a total of 9 stars. Studies with a total score of $\leq 5$ stars, 6-7 stars, and 8-9 stars were considered to be of low quality, intermediate quality, and high quality respectively. All included studies had an intermediate or high quality according to NOS.

\section{The assessment of PS}

Eastern Cooperative Oncology Group performance status (ECOG PS) scale and Karnofsky performance status (KPS) scale are the two most widely used measurement instruments to evaluate the performance status of mRCC patients [28-31]. The KPS scale rating ranges from 100, indicating that all functions can perform normal daily activities without clinical evidence (symptoms or signs), to 0 , which means death [10]. ECOG introduced the ECOG PS scale with only 6 points, which was a more simplified scale ranging from 0 (fully active) to 5 (death) [32]. In view of the fact that the cut-off values classified in practical applications were not completely consistent, we defined poor PS as the group with lower KPS scale scores or the group with higher ECOG PS scale scores, while others were considered to be good PS.

\section{Statistical analysis}

We performed a formal meta-analysis of OS and PFS. HRs with 95\% CIs from each study were used to calculate combined HRs. Cochrane's $Q$ test and Higgins $I^{2}$ statistic were used to assess the heterogeneity across the studies. The studies with $P>0.1$ and $I^{2}<50 \%$ were considered indicative of significant heterogeneity. If no significant heterogeneity was found, a pooled estimate was calculated with a fixed effect model; or, a random effect model was used. The Begg's funnel plot and Egger's linear regression teats were used to evaluate the potential publication bias. A sensitivity analysis was performed to evaluate the stability of the results and to reduce the effect of individual studies on final conclusions. Two-tailed value 
of $P<0.05$ was considered statistically significant. The meta-analysis was performed with RevMan 5.3 and Stata SE12.0 (Stata Corp LP, College Station, TX, USA) according to the PRISMA guidelines [33].

\section{Results}

A total of 852 articles were identified from electronic databases (PubMed, Embase and the Cochrane Library) and 3 additional studies were identified from reference lists. Sixty duplicate articles were removed. After a careful review of titles and abstracts, 731 articles were excluded for not relevant, other urinary cancer, laboratory studies, reviews, letters and comments. After assessing the full text of the remaining 64 articles, 45 articles were excluded for some specific reasons, including not TKI treatment, not evaluate the association between PS and survival outcome, involving other targeted therapies, not available hazard ratio, duplicate data and not English articles. Finally, 19 retrospective cohort studies [17-26, 34-42] were included in the following meta-analysis. Figure 1 shows the full screening procedure.

\section{The features of included studies}

The characteristics of the included studies are shown in Table 1. These 19 articles were published between 2010 and 2018. Among them, 11 were published before 2015 and 8 were published in the past 3 years. Seven, nine and three studies were conducted in Asian, Europe and America, respectively. Sample size of included studies ranged from 39 to 4543 patients, and a total of 6780 patients were included. All trials were conducted in adult patients who received TKIs. The mean (median) age of the subjects ranged from 57 to 68.8 years, and the percentage of included males ranged from 65.6 to $82.9 \%$. Clear cell carcinoma accounted for 62.5 to $100 \%$ of all pathological types. Eleven of the 19 studies used ECOG PS scale to assess PS and another eight used KPS scale. Six articles reported the prognostic value of PS for both OS and PFS in patients with $\mathrm{mRCC}$ receiving TKIs, 11 articles only reported OS and 2 other articles only reported PFS.

The cut-off value of the 6 studies using KPS scale to evaluate the patient's PS was $80 \%$, and the other 2 studies were $70 \%[37,42]$. Of the 11 studies using ECOG PS scale, 8 had a cut-off value of 1 and the other 3 had a cut-off value of 2 [17-19].

\section{Survival outcomes}

Prognostic outcomes, including OS and PFS, were quantitatively synthesized. The impact of PS on OS was

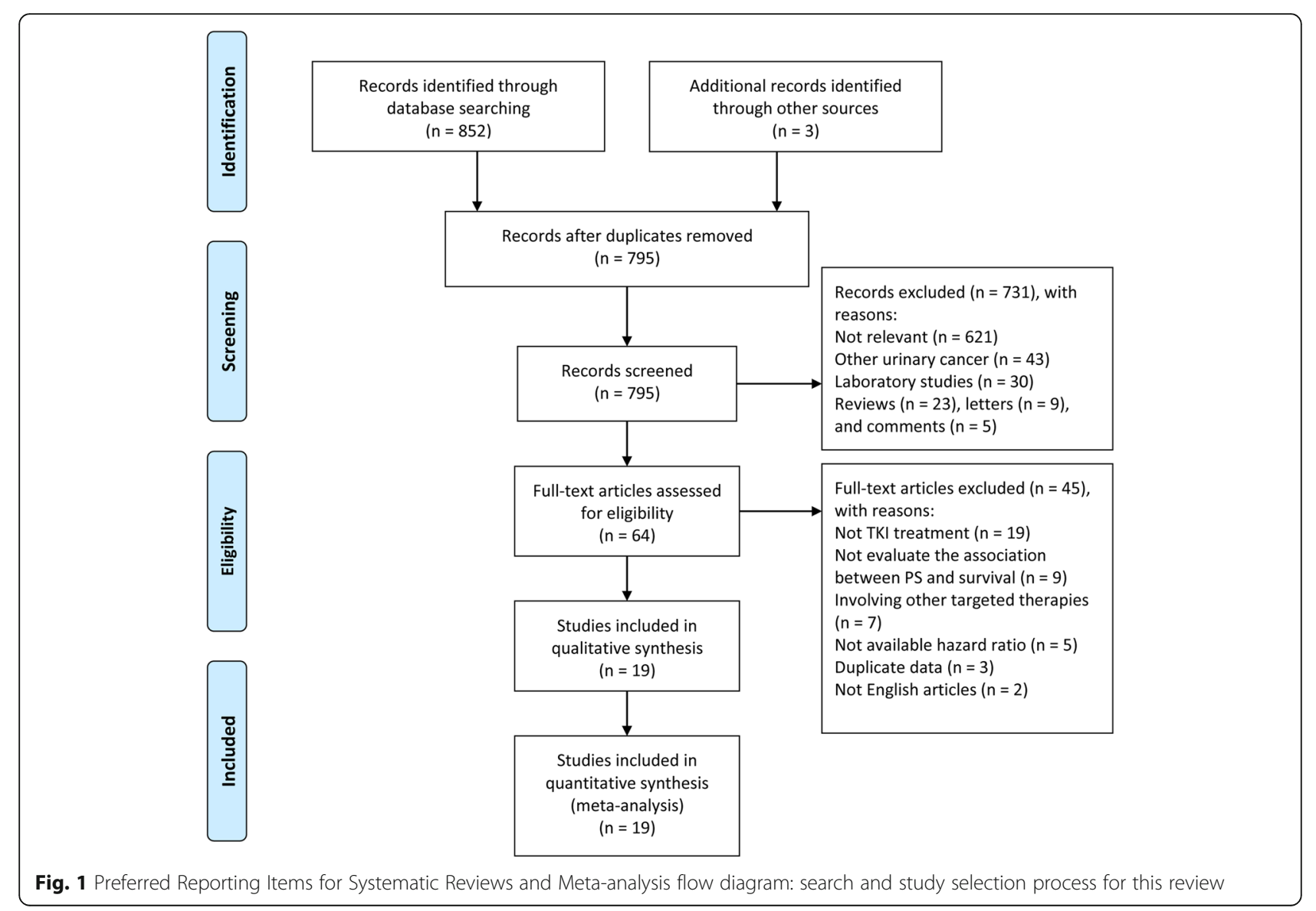




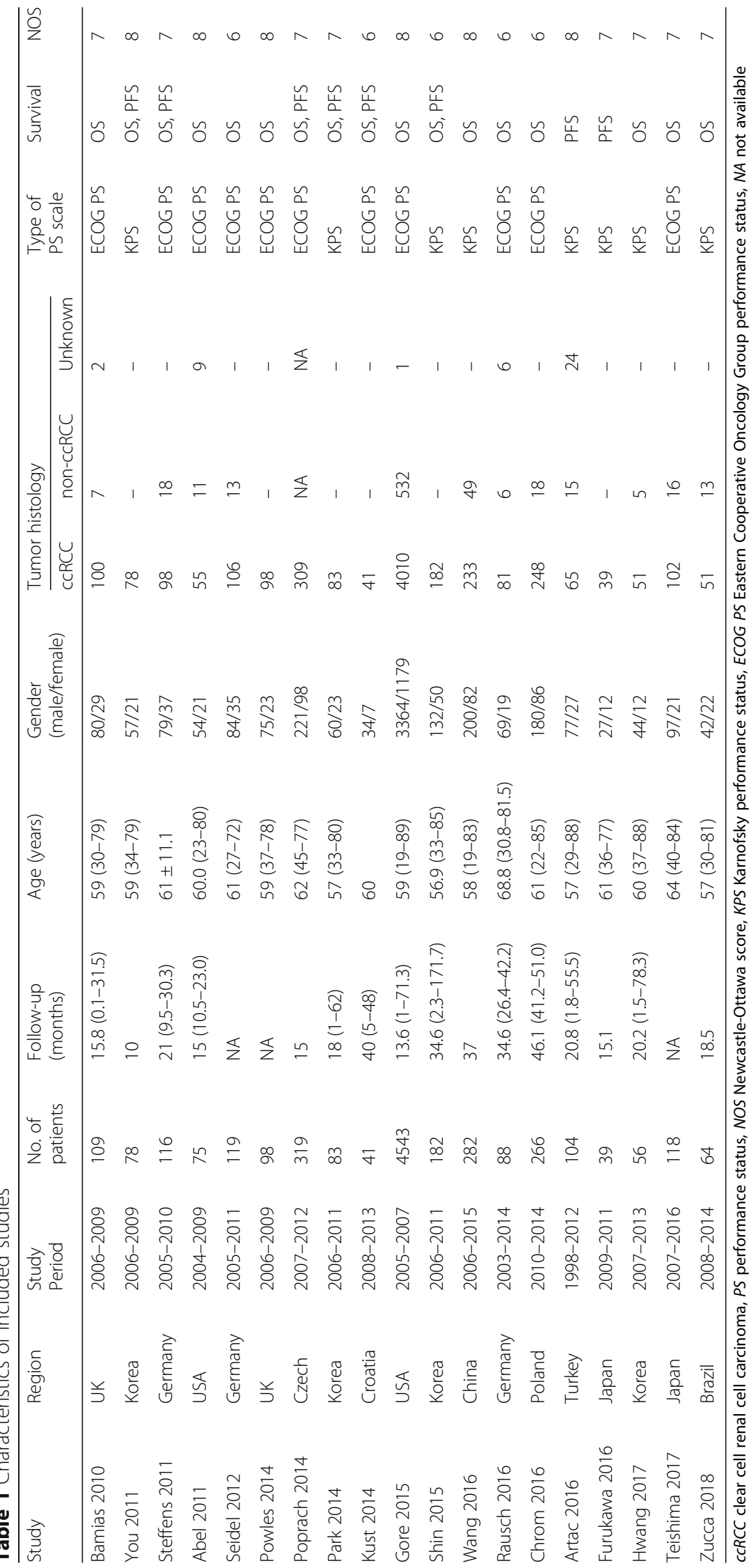


investigated in 17 studies including $6637 \mathrm{mRCC}$ patients receiving TKIs. The forest plot (Fig. 2a) shows that poor PS was significantly associated with poor OS (pooled HR: 2.08, 95\% CI: 1.78-2.45). The Cochrane $Q$ test $\left(C h i^{2}=17.34, P=0.36\right)$ and $I^{2}$ test $\left(I^{2}=8 \%\right)$ did not show significant heterogeneity.

The impact of PS on PFS was investigated in 8 studies including $962 \mathrm{mRCC}$ patients receiving TKIs. The forest plot (Fig. 2b) shows that poor PS was significantly associated with poor PFS (pooled HR: 1.51, 95\% CI: $1.20-1.91)$. The Cochrane $Q$ test $\left(C h i^{2}=9.33\right.$, $P=0.23)$ and $I^{2}$ test $\left(I^{2}=25 \%\right)$ did not show significant heterogeneity.

\section{Subgroup analysis}

Table 2 summarizes the results of subgroup analysis according to the type of PS scale, study setting, year of publication and NOS score. Pooled analysis of studies with KPS associated with worse OS (pooled HR: $\left.2.20,95 \% \mathrm{CI}: 1.65-2.94 ; P=0.26, I^{2}=24 \%\right)$ and PFS (pooled HR: 1.74, 95\% CI: $1.19-2.56 ; P=0.50$, $\left.I^{2}=0\right)$ than ECOG PS. Subgroup analysis according to study setting revealed that Asian studies associated with worse OS (pooled HR: 2.25, 95\% CI: $1.71-2.95 ; P=0.24, I^{2}=26$ ) and PFS (pooled HR: 1.73, 95\% CI: $1.14-2.64 ; P=0.34, I^{2}=11$ ) than European and American studies. Pooled HRs for survival outcome stratified by the NOS score showed that worse OS (pooled HR: 2.61, 95\% CI: 1.92-3.55; $P=$ 0.90, $I^{2}=0$ ) and PFS (pooled HR: 2.43, 95\% CI: $\left.1.36-4.33 ; P=0.43, I^{2}=0\right)$ in studies with an NOS score of 8 . Due to the small number of literatures, no further subgroup analysis can be conducted on the studies that focus on PFS.

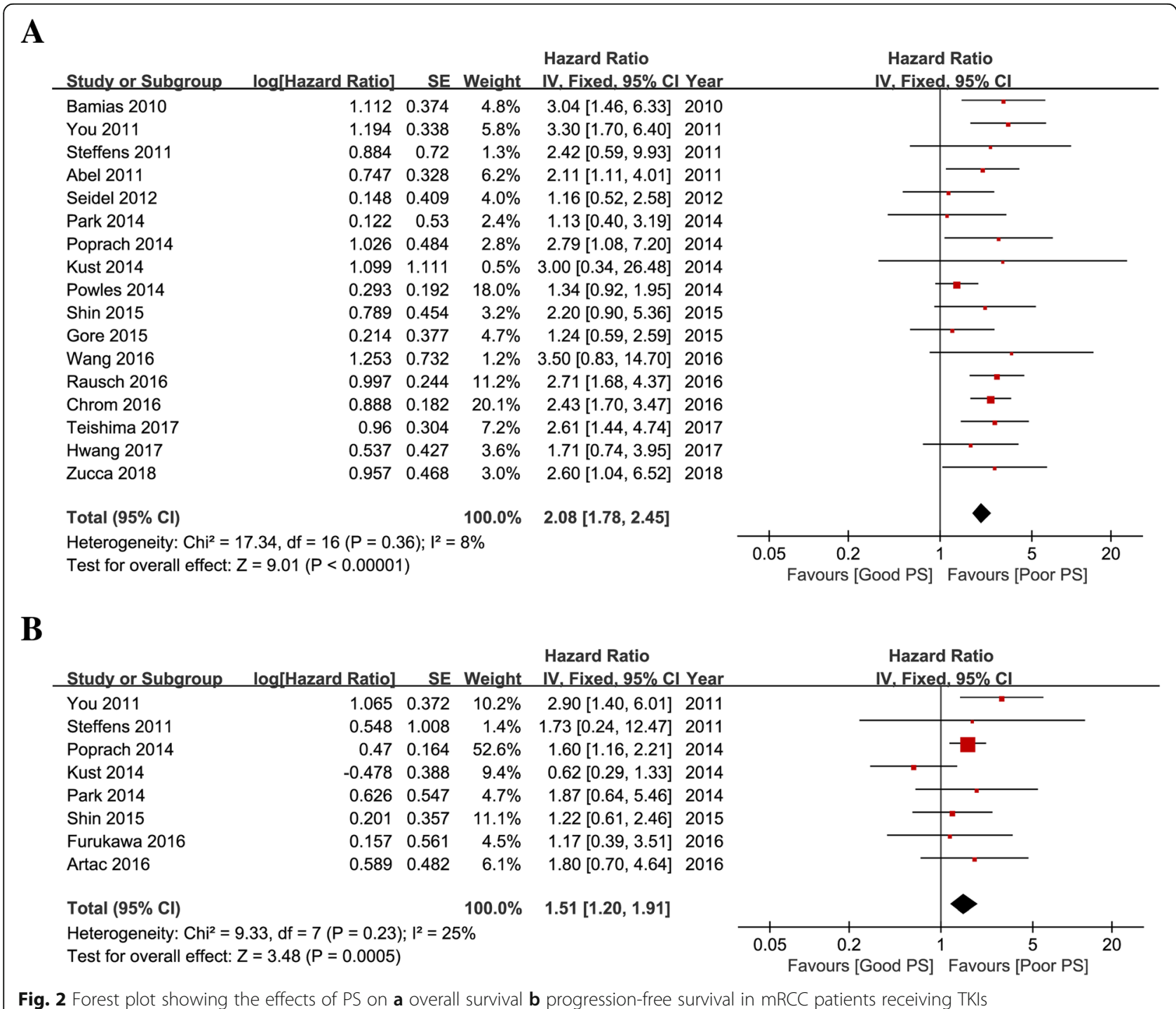


Table 2 Subgroup analyses for the association between PS and the survival

\begin{tabular}{|c|c|c|c|c|c|c|c|c|c|c|}
\hline \multirow{3}{*}{$\begin{array}{l}\text { Subgroup } \\
\text { analysis }\end{array}$} & \multicolumn{5}{|l|}{ OS } & \multicolumn{5}{|l|}{ PFS } \\
\hline & \multirow{2}{*}{$\begin{array}{l}\text { No. of } \\
\text { studies }\end{array}$} & \multirow{2}{*}{$\begin{array}{l}\text { Pooled HR } \\
(95 \% \mathrm{Cl})\end{array}$} & \multirow[t]{2}{*}{$P$ value } & \multicolumn{2}{|c|}{ Heterogeneity } & \multirow{2}{*}{$\begin{array}{l}\text { No. of } \\
\text { studies }\end{array}$} & \multirow{2}{*}{$\begin{array}{l}\text { Pooled HR } \\
(95 \% \mathrm{Cl})\end{array}$} & \multirow{2}{*}{$\begin{array}{l}P \\
\text { value }\end{array}$} & \multicolumn{2}{|c|}{ Heterogeneity } \\
\hline & & & & $P^{2}(\%)$ & $P$ & & & & $P(\%)$ & $P$ \\
\hline Overall & 17 & $2.08(1.78-2.45)$ & $<0.00001$ & 8 & 0.36 & 8 & $1.51(1.20-1.91)$ & 0.0005 & 25 & 0.23 \\
\hline \multicolumn{11}{|l|}{ Type of PS scale } \\
\hline KPS & 6 & $2.20(1.65-2.94)$ & $<0.00001$ & 24 & 0.26 & 5 & $1.74(1.19-2.56)$ & 0.005 & 0 & 0.50 \\
\hline ECOG PS & 11 & $2.03(1.68-2.46)$ & $<0.00001$ & 6 & 0.39 & 3 & $1.39(1.04-1.87)$ & 0.03 & 61 & 0.08 \\
\hline \multicolumn{11}{|l|}{ Study setting } \\
\hline Asia & 6 & $2.25(1.71-2.95)$ & $<0.00001$ & 26 & 0.24 & 4 & $1.73(1.14-2.64)$ & 0.01 & 11 & 0.34 \\
\hline Europe & 8 & $1.95(1.56-2.43)$ & $<0.00001$ & 28 & 0.20 & 4 & $1.42(1.08-1.88)$ & 0.01 & 44 & 0.15 \\
\hline America & 3 & $2.25(1.43-3.53)$ & 0.0005 & 0 & 0.93 & 0 & - & - & - & - \\
\hline \multicolumn{11}{|c|}{ Year of publication } \\
\hline Before 2015 & 11 & $1.79(1.44-2.22)$ & $<0.00001$ & 17 & 0.28 & 6 & $1.51(1.18-1.94)$ & 0.001 & 44 & 0.11 \\
\hline After 2015 & 6 & 2.49 (1.97-3.15) & $<0.00001$ & 0 & 0.95 & 2 & $1.50(0.73-3.07)$ & 0.27 & 0 & 0.56 \\
\hline \multicolumn{11}{|l|}{ NOS score } \\
\hline 6 & 5 & $2.07(1.57-2.74)$ & $<0.00001$ & 28 & 0.24 & 2 & $0.90(0.54-1.50)$ & 0.67 & 40 & 0.20 \\
\hline 7 & 7 & $1.80(1.40-2.32)$ & $<0.00001$ & 19 & 0.29 & 4 & $1.57(1.18-2.10)$ & 0.002 & 0 & 0.92 \\
\hline 8 & 5 & $2.61(1.92-3.55)$ & $<0.00001$ & 0 & 0.90 & 2 & $2.43(1.36-4.33)$ & 0.003 & 0 & 0.43 \\
\hline
\end{tabular}

OS overall survival, PFS progression-free survival, PS performance status, KPS Karnofsky performance status, ECOG PS Eastern Cooperative Oncology Group performance status, NOS Newcastle-Ottawa score, Cl confidence interval

\section{Publication bias}

Begg's funnel plots test and Egger's test were used to assess the publication bias in this meta-analysis (Fig. 3). Both Begg's funnel plots test (OS: $P=0.773$, PFS $=0.711)$ and Egger's test (OS: $P=0.671$, $P F S=0.834$ ) verified that no obvious publication bias exists.

\section{Sensitivity analysis}

A sensitivity analysis was performed to evaluate the stability of the results and to reduce the effect of individual studies on final conclusions (Fig. 4). The test suggested that the pooled results did not tend to alter when a study was excluded.
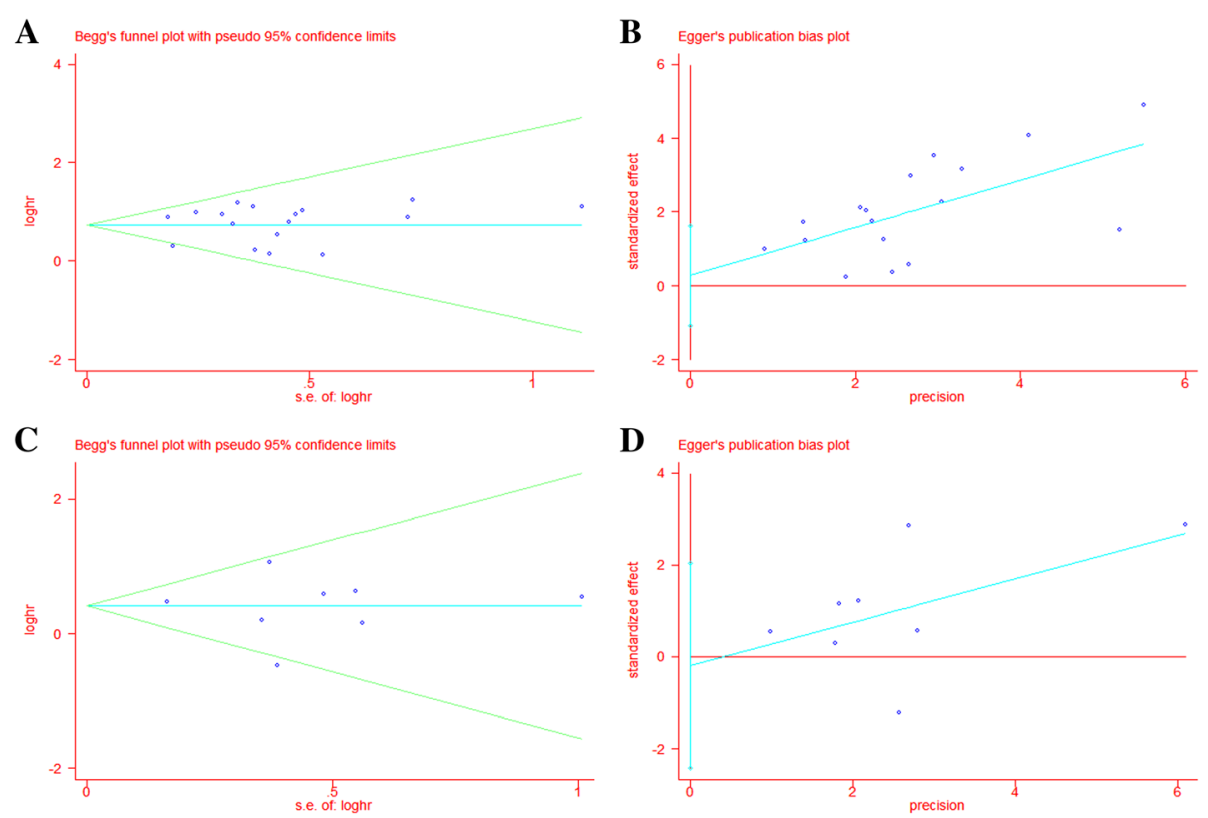

Fig. 3 Funnel plots based on overall survival a Begg's test b Egger's test; and progression-free survival c Begg's test d Egger's test 


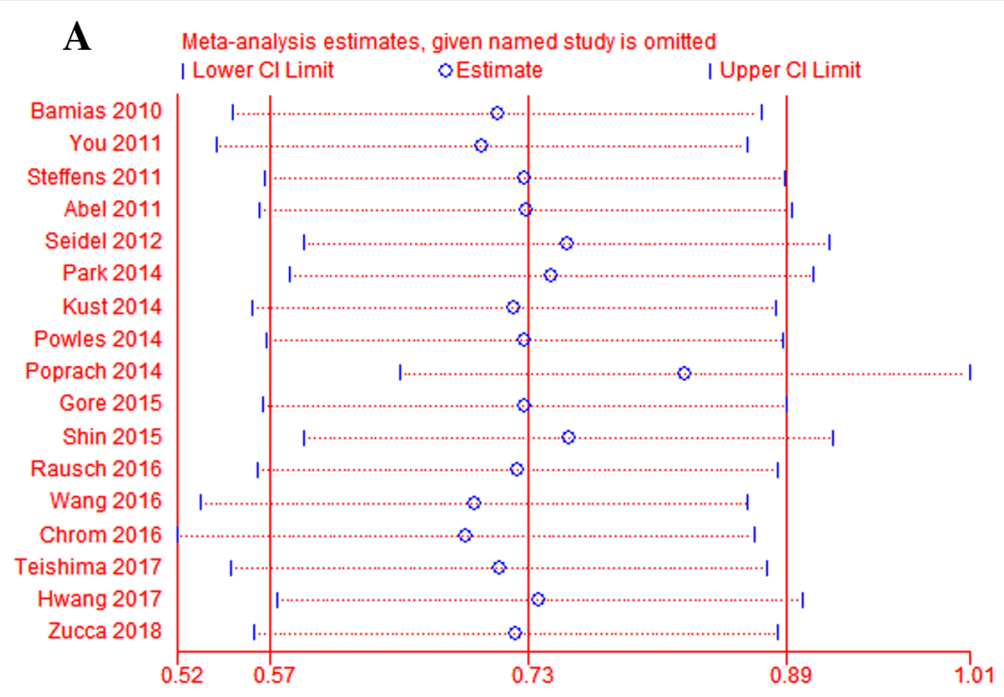

B Meta-analysis estimates, given named study is omitted

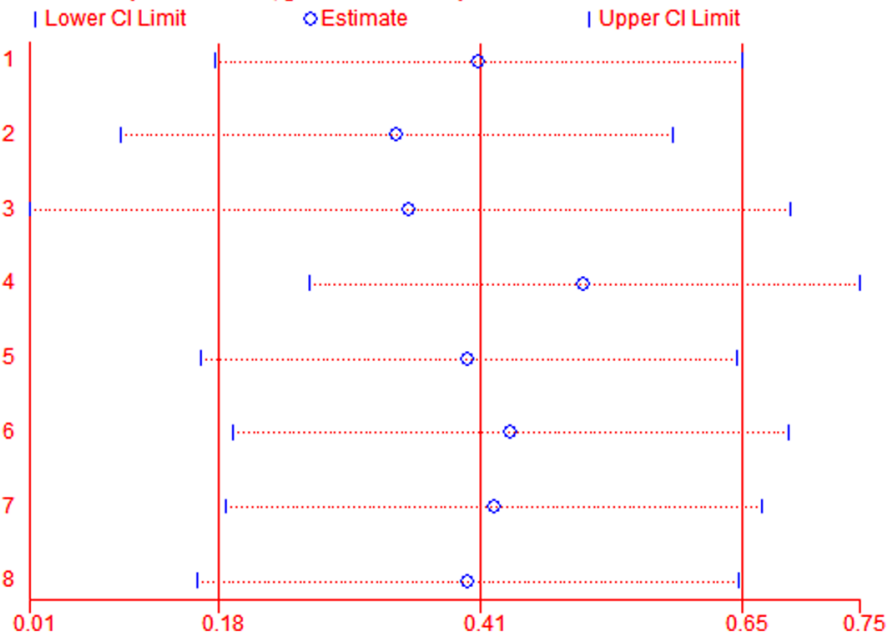

Fig. 4 Sensitivity analysis in this mate-analysis. a sensitivity analysis for overall survival; $\mathbf{b}$ sensitivity analysis for progression-free survival

\section{Discussion}

Since applying TKIs to the management of mRCC patients, the prognosis of these patients has been significantly improved compared to that in the era of cytokine therapy $[43,44]$. The introduction of these drugs has induced a dramatic paradigm shift in the treatment of mRCC. These molecular targeted agents need novel factors that precisely reflect susceptibility to TKIs, thereby providing individualized risk-directed treatment for patients with mRCC. To date, several model systems predicting the prognosis of patients with $\mathrm{mRCC}$ in the era of immunotherapy have been reported [14, 45, 46]; in particular, the Memorial Sloan-Kettering Cancer Center (MSKCC) scoring system is still applied to patients receiving TKIs era [17]. However, these models were based on traditional markers of risk, rather than molecular characteristics.

This meta-analysis based on currently available clinical evidence adjusted clinical and demographic variables that may have affected survival outcomes. We found that poor PS may significantly predict unfavorable prognostic outcomes in mRCC patients receiving TKIs and may play an important role in the management of mRCC patients. Although the International Metastatic Renal Cell Carcinoma Database Consortium (IMDC) [19] and MSKCC [17] risk models are being used to predict the prognosis of mRCC patients, PS is expected to be a simpler indictor for screening of mRCC patients who received TKIs in clinical practice.

PS was used to quickly quantify the general health status of the patient population and their ability to perform daily activities [11, 47]. It is usually a proxy measure estimated by the clinician or researcher and affects the decision to apply the management plan, especially in terms of conservative and non-conservative care and planning for self-care. PS has been reported to be associated with the survival outcomes of several malignancies, such as 
bladder cancer [12], hepatocellular carcinoma [13], and non-small-cell lung cancer [11]. PS has been regarded as a key determinant of the malignant tumor patients' ability to undergo therapy.

Many previous studies have consistently identified that PS was a significant prognostic factor in patients with RCC [14-16]. In a retrospective study of 670 patients with RCC [14], median survival time was $2.7,6.1,10.6$ and 14.4 months for patients with Karnofsky PS (KPS) of 60, 70, 80 and $90 \%$, respectively $(P<0.0001)$. As well, another study identified ECOG PS as an independent prognostic factor for survival in a multivariate analysis of 782 patients of mRCC [48]. However, the prognostic value of PS in patients with mRCC treated with TKIs was controversial.

There are some limitations in our meta-analysis. First, all the included studies in this meta-analysis were retrospective, which may lead to selection bias. High-quality prospective researches needed to further investigation in this field. Second, the simple size of partial eligible was relatively small. The large-scale studies are necessary to achieve more credible results in the future. Finally, the potential heterogeneity might still exist. Although heterogeneity was not significantly from the results of meta-analysis and subgroup analysis, but the cut-off values across the included studies were not completely consistent, which might lead to unknown heterogeneity. Therefore, more uniform standards should be established to increase homogeneity between the studies.

\section{Conclusions}

To conclude, the present meta-analysis demonstrates that poor PS may significantly predict unfavorable prognostic outcomes in mRCC patients receiving TKIs. Therefore, PS may play an important role in the management of mRCC patients. However, in order to better evaluate the prognostic value of PS in mRCC patients treated with TKIs, additional prospective, large-scale, and homogeneous clinical studies will be needed in the future.

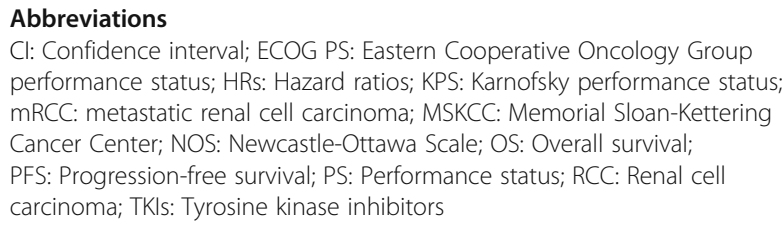

\section{Acknowledgements}

Not applicable.

Funding

The authors declare no funding.

\section{Availability of data and materials}

The datasets used and/or analyzed during the current study are available from the corresponding author on reasonable request.

\section{Authors' contributions}

$X Q L$ and $Y W X$ designed this study; YWX and YYZ searched electronic databases and selected studies; YYZ and XHW extracted the data; YYZ and YWX were responsible for checking the extracted data; $X Q L$ and $Y W X$ performed the quality assessment; XHW and JQK analyzed the data; YYZ and YWX wrote the manuscript. All authors reviewed and approved the manuscript.

\section{Ethics approval and consent to participate}

All the procedures performed were in full accordance with the ethical standards of the appropriate national and institutional committees on human experimentation and with the Helsinki Declaration. This study was approved by the institution Ethics Commission of Tianjin Medical University General Hospital and the Second Hospital of Tianjin Medical University. The need for consent to participate was waived by Ethics Commission of Tianjin Medical University General Hospital and the Second Hospital of Tianjin Medical University.

Consent for publication

Not applicable.

Competing interests

All authors declare that they have no competing interests.

\section{Publisher's Note}

Springer Nature remains neutral with regard to jurisdictional claims in published maps and institutional affiliations.

\section{Author details}

'Department of Urology, Tianjin Medical University General Hospital, 154 Anshan Road, Heping District, Tianjin 300052, China. ${ }^{2}$ Department of Thyroid Surgery, The First Affiliated Hospital of Zhengzhou University, Zhengzhou, Henan, China.

Received: 26 August 2018 Accepted: 18 February 2019

Published online: 22 February 2019

\section{References}

1. Siegel R, Naishadham D, Jemal A. Cancer statistics, 2012. CA Cancer J Clin. 2012;62(1):10-29.

2. Theis RP, Dolwick Grieb SM, Burr D, Siddiqui T, Asal NR. Smoking, environmental tobacco smoke, and risk of renal cell cancer: a populationbased case-control study. BMC Cancer. 2008;8:387.

3. Gupta K, Miller JD, Li JZ, Russell MW, Charbonneau C. Epidemiologic and socioeconomic burden of metastatic renal cell carcinoma (mRCC): a literature review. Cancer Treat Rev. 2008;34(3):193-205.

4. Thomas JS, Kabbinavar F. Metastatic clear cell renal cell carcinoma: a review of current therapies and novel immunotherapies. Crit Rev Oncol Hematol. 2015;96(3):527-33.

5. Motzer RJ, Hutson TE, Tomczak P, Michaelson MD, Bukowski RM, Rixe O, Oudard S, Negrier S, Szczylik C, Kim ST, et al. Sunitinib versus interferon alfa in metastatic renal-cell carcinoma. N Engl J Med. 2007;356(2):115-24.

6. Sternberg CN, Davis ID, Mardiak J, Szczylik C, Lee E, Wagstaff J, Barrios CH, Salman P, Gladkov OA, Kavina A, et al. Pazopanib in locally advanced or metastatic renal cell carcinoma: results of a randomized phase III trial. J Clin Oncol. 2010;28(6):1061-8.

7. Rini Bl, Escudier B, Tomczak P, Kaprin A, Szczylik C, Hutson TE, Michaelson MD, Gorbunova VA, Gore ME, Rusakov IG, et al. Comparative effectiveness of axitinib versus sorafenib in advanced renal cell carcinoma (AXIS): a randomised phase 3 trial. Lancet (London, England). 2011;378(9807):1931-9.

8. Collinson FJ, Gregory WM, McCabe C, Howard H, Lowe C, Potrata D, Tubeuf S, Hanlon P, McParland L, Wah T, et al. The STAR trial protocol: a randomised multi-stage phase II/III study of Sunitinib comparing temporary cessation with allowing continuation, at the time of maximal radiological response, in the first-line treatment of locally advanced/metastatic renal cancer. BMC Cancer. 2012;12:598.

9. Zhang $X$, Yang B, Li N, Li H. Prevalence and risk factors for erectile dysfunction in Chinese adult males. J Sex Med. 2017;14(10):1201-8.

10. Schag CC, Heinrich RL, Ganz PA. Karnofsky performance status revisited: reliability, validity, and guidelines. J Clin Oncol. 1984;2(3):187-93. 
11. Dajczman E, Kasymjanova G, Kreisman H, Swinton N, Pepe C, Small D. Should patient-rated performance status affect treatment decisions in advanced lung cancer? J Clin Oncol. 2008;3(10):1133-6.

12. Hinata N, Miyake H, Miyazaki A, Nishikawa M, Tei H, Fujisawa M. Performance status as a significant prognostic predictor in patients with urothelial carcinoma of the bladder who underwent radical cystectomy. Int J Urol. 2015;22(8):742-6.

13. Hsu CY, Lee YH, Hsia CY, Huang YH, Su CW, Lin HC, Lee RC, Chiou YY, Lee FY, Huo TI. Performance status in patients with hepatocellular carcinoma: determinants, prognostic impact, and ability to improve the Barcelona Clinic Liver Cancer system. Hepatology (Baltimore, Md). 2013;57(1):112-9.

14. Motzer RJ, Mazumdar M, Bacik J, Berg W, Amsterdam A, Ferrara J. Survival and prognostic stratification of 670 patients with advanced renal cell carcinoma. J Clin Oncol. 1999;17(8):2530-40.

15. Motzer RJ, Bacik J, Schwartz LH, Reuter V, Russo P, Marion S, Mazumdar M. Prognostic factors for survival in previously treated patients with metastatic renal cell carcinoma. J Clin Oncol. 2004;22(3):454-63.

16. Kim HL, Han KR, Zisman A, Figlin RA, Belldegrun AS. Cachexia-like symptoms predict a worse prognosis in localized t1 renal cell carcinoma. J Urol. 2004; 171(5):1810-3.

17. Bamias A, Karadimou A, Lampaki S, Lainakis G, Malettou L, Timotheadou E, Papazisis K, Andreadis C, Kontovinis L, Anastasiou I, et al. Prognostic stratification of patients with advanced renal cell carcinoma treated with sunitinib: comparison with the memorial Sloan-Kettering prognostic factors model. BMC Cancer. 2010;10:45.

18. Abel EJ, Culp SH, Tannir NM, Tamboli P, Matin SF, Wood CG. Early primary tumor size reduction is an independent predictor of improved overall survival in metastatic renal cell carcinoma patients treated with sunitinib. Eur Urol. 2011;60(6):1273-9.

19. Gore ME, Szczylik C, Porta C, Bracarda S, Bjarnason GA, Oudard S, Lee SH, Haanen J, Castellano D, Vrdoljak E, et al. Final results from the large sunitinib global expanded-access trial in metastatic renal cell carcinoma. Br J Cancer. 2015;113(1):12-9.

20. You D, Jeong IG, Ahn JH, Lee DH, Lee JL, Hong JH, Ahn H, Kim CS. The value of cytoreductive nephrectomy for metastatic renal cell carcinoma in the era of targeted therapy. J Urol. 2011;185(1):54-9.

21. Kust D, Prpic M, Murgic J, Jazvic M, Jaksic B, Krilic D, Bolanca A, Kusic Z. Hypothyroidism as a predictive clinical marker of better treatment response to sunitinib therapy. Anticancer Res. 2014;34(6):3177-84.

22. Poprach A, Pavlik T, Melichar B, Kubackova K, Bortlicek Z, Svoboda M, Lakomy R, Vyzula R, Kiss I, Dusek L, et al. Clinical and laboratory prognostic factors in patients with metastatic renal cell carcinoma treated with sunitinib and sorafenib after progression on cytokines. Urol Oncol. 2014;32(4):488-95.

23. Rausch S, Kruck S, Walter K, Stenzl A, Bedke J. Metastasectomy for metastatic renal cell carcinoma in the era of modern systemic treatment: $C$-reactive protein is an independent predictor of overall survival. Int J Urol. 2016;23(11):916-21.

24. Park JY, Lee JL, Baek S, Eo SH, Go H, Ro JY, Cho YM. Sarcomatoid features, necrosis, and grade are prognostic factors in metastatic clear cell renal cel carcinoma with vascular endothelial growth factor-targeted therapy. Hum Pathol. 2014;45(7):1437-44.

25. Seidel C, Busch J, Weikert S, Steffens S, Fenner M, Ganser A, Grunwald V. Progression free survival of first line vascular endothelial growth factortargeted therapy is an important prognostic parameter in patients with metastatic renal cell carcinoma. Eur J Cancer. 2012;48(7):1023-30.

26. Hwang SH, Cho A, Yun M, Choi YD, Rha SY, Kang WJ. Prognostic value of pretreatment metabolic tumor volume and Total lesion glycolysis using 18F-FDG PET/CT in patients with metastatic renal cell carcinoma treated with anti-vascular endothelial growth factor-targeted agents. Clin Nucl Med. 2017;42(5):e235-41.

27. Stang A. Critical evaluation of the Newcastle-Ottawa scale for the assessment of the quality of nonrandomized studies in meta-analyses. Eur J Epidemiol. 2010;25(9):603-5.

28. Hsieh JJ, Chen D, Wang PI, Marker M, Redzematovic A, Chen YB, Selcuklu SD, Weinhold N, Bouvier N, Huberman KH, et al. Genomic biomarkers of a randomized trial comparing first-line Everolimus and Sunitinib in patients with metastatic renal cell carcinoma. Eur Urol. 2017;71(3):405-14.

29. Escudier B, Motzer RJ, Sharma P, Wagstaff J, Plimack ER, Hammers HJ, Donskov F, Gurney H, Sosman JA, Zalewski PG, et al. Treatment beyond progression in patients with advanced renal cell carcinoma treated with Nivolumab in CheckMate 025. Eur Urol. 2017;72(3):368-76.

30. Shvarts O, Lam JS, Kim HL, Han KR, Figlin R, Belldegrun A. Eastern cooperative oncology group performance status predicts bone metastasis in patients presenting with renal cell carcinoma: implication for preoperative bone scans. J Urol. 2004;172(3):867-70.

31. Park J, Jiao X, Ghate S, Wilson T, Ahmad Ql, Vogelzang NJ. Predictors of Long-Term Response With Pazopanib in Patients With Advanced Renal-Cell Carcinoma. Clin Genitourin Cancer. 2018;16(4):293-7.

32. Oken MM, Creech RH, Tormey DC, Horton J, Davis TE, McFadden ET, Carbone PP. Toxicity and response criteria of the eastern cooperative oncology group. Am J Clin Oncol. 1982;5(6):649-55.

33. Knobloch $\mathrm{K}$, Yoon U, Vogt PM. Preferred reporting items for systematic reviews and meta-analyses (PRISMA) statement and publication bias. J Craniomaxillofac Surg. 2011;39(2):91-2.

34. Steffens S, Grunwald V, Ringe Kl, Seidel C, Eggers H, Schrader M, Wacker F, Kuczyk MA, Schrader AJ. Does obesity influence the prognosis of metastatic renal cell carcinoma in patients treated with vascular endothelial growth factor-targeted therapy? Oncologist. 2011;16(11):1565-71.

35. Powles T, Kayani I, Sharpe K, Lim L, Peters J, Stewart GD, Berney D, Sahdev A, Chowdhury S, Boleti E, et al. A prospective evaluation of VEGF-targeted treatment cessation in metastatic clear cell renal cancer. Ann Oncol. 2013; 24(8):2098-103.

36. Shin SJ, Jeon YK, Cho YM, Lee JL, Chung DH, Park JY, Go H. The association between PD-L1 expression and the clinical outcomes to vascular endothelial growth factor-targeted therapy in patients with metastatic clear cell renal cell carcinoma. Oncologist. 2015;20(11):1253-60.

37. Wang HK, Wan FN, Gu WJ, Zhu Y, Dai B, Shi GH, Zhang HL, Ye DW. Eosinophil percentage elevation as a prognostic factor for overall survival in patients with metastatic renal cell carcinoma treated with tyrosine kinase inhibitor. Oncotarget. 2016;7(42):68943-53.

38. Chrom P, Stec R, Semeniuk-Wojtas A, Bodnar L, Spencer NJ, Szczylik C. Fuhrman grade and neutrophil-to-lymphocyte ratio influence on survival in patients with metastatic renal cell carcinoma treated with first-line tyrosine kinase inhibitors. Clin Genitourin Cancer. 2016;14(5):457-64.

39. Artac M, Coskun HS, Korkmaz L, Kocer M, Turhal NS, Engin H, Dede I, Paydas S, Oksuzoglu B, Bozcuk $H$, et al. Using interferon alfa before tyrosine kinase inhibitors may increase survival in patients with metastatic renal cell carcinoma: a Turkish oncology group (TOG) study. Clin Genitourin Cancer. 2016;14(4):e347-53.

40. Furukawa J, Miyake H, Fujisawa M. GLI2 expression levels in radical nephrectomy specimens as a predictor of disease progression in patients with metastatic clear cell renal cell carcinoma following treatment with sunitinib. Mol Clin Oncol. 2016;5(3):186-92.

41. Teishima J, Kobatake K, Shinmei S, Inoue S, Hayashi T, Ohara S, Mita K, Hasegawa Y, Maruyama S, Kajiwara M, et al. The effect of kinetics of Creactive protein in the prediction of overall survival in patients with metastatic renal cell carcinoma treated with tyrosine kinase inhibitor. Urologic Oncol. 2017;35(11):662.e661-7.

42. Zucca LE, Morini Matushita MA, da Silva Oliveira RJ, Scapulatempo-Neto C, de Lima MA, Ribeiro GG, Viana CR, Carcano FM, Reis RM. Expression of tyrosine kinase receptor $A X L$ is associated with worse outcome of metastatic renal cell carcinomas treated with sunitinib. Urologic Oncol. 2018;36(1):11.e13-21.

43. Zhang HL, Sheng XN, Li XS, Wang HK, Chi ZH, He ZS, Ye DW, Guo J. Sorafenib versus sunitinib as first-line treatment agents in Chinese patients with metastatic renal cell carcinoma: the largest multicenter retrospective analysis of survival and prognostic factors. BMC Cancer. 2017;17(1):16.

44. Lakomy R, Poprach A, Bortlicek Z, Melichar B, Chloupkova R, Vyzula R, Zemanova M, Kopeckova K, Svoboda M, Slaby O, et al. Utilization and efficacy of second-line targeted therapy in metastatic renal cell carcinoma: data from a national registry. BMC Cancer. 2017;17(1):880.

45. Motzer RJ, Bacik J, Murphy BA, Russo P, Mazumdar M. Interferon-alfa as a comparative treatment for clinical trials of new therapies against advanced renal cell carcinoma. J Clin Oncol. 2002;20(1):289-96.

46. Fyfe G, Fisher RI, Rosenberg SA, Sznol M, Parkinson DR, Louie AC. Results of treatment of 255 patients with metastatic renal cell carcinoma who received high-dose recombinant interleukin-2 therapy. J Clin Oncol. 1995;13(3):688-96.

47. Jeyasingam L, Agar M, Soares M, Plummer J, Currow DC. A prospective study of unmet activity of daily living needs in palliative care inpatients. Aust Occup Ther J. 2008:55(4):266-72.

48. Negrier S, Escudier B, Gomez F, Douillard JY, Ravaud A, Chevreau C, Buclon M, Perol D, Lasset C. Prognostic factors of survival and rapid progression in 782 patients with metastatic renal carcinomas treated by cytokines: a report from the Groupe Francais d'Immunotherapie. Ann Oncol. 2002;13(9):1460-8. 